Journal of Applied Pharmaceutical Science Vol. 6 (10), pp. 226-230, October, 2016

Available online at http://www.japsonline.com

DOI: $10.7324 / J A P S .2016 .601032$

ISSN 2231-3354 (cc) BY-NC-SA

\title{
Antimicrobial activity of Korean camellia mistletoe (Korthalsella japonica (Thunb.) Engl.) extracts
}

\author{
Da Hee Kang, Min Young Kim* \\ Toxicology Laboratory, Major in Biomaterials, College of Applied Life Science, SARI, Jeju National University, Jeju, Republic of Korea.
}

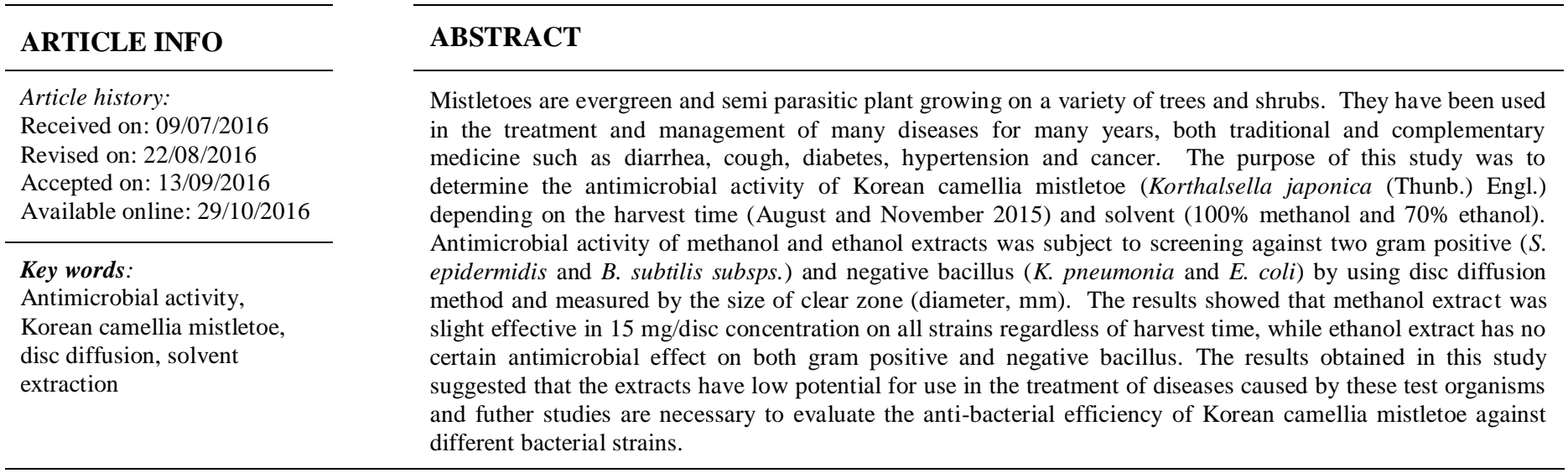

\section{INTRODUCTION}

Plants and their secondary metabolites possess antimicrobial, antifungal or antiviral activities. The various plant products, that are regularly used for their therapeutic potential, and plant or plant products that form the part of the food or as dietary components, have been receiving considerable attention (Cowan, 2009). However, not many reports are available on the exploitation of antifungal or antibacterial property of plants for developing commercial formulations for applications in crop protection, pharmaceutical and food processing (Balandrin et al., 1985; Cowan, 2009). Furthermore, nowadays most of the antibiotics and food preservatives are obtained by various synthetic processes (Reiner, 1984). Mistletoe is general term for woody shoot parasites in several plant families that also known as medical plant.

\footnotetext{
* Corresponding Author

Min Young Kim, Toxicology Laboratory, Major in Biomaterials, College of Applied Life Science, SARI, Jeju National University, Jeju, Republic of Korea. Tel: 82-64-754-3349; Fax: 82-64-756-3351

Email: jeffmkim @ jejunu.ac.kr
}

The typical farmer or gardener sees mistletoes as notorious and devastating parasites which pose serious losses toeconomically-valuable fruit trees and medicinal plants whether growing in wild forests, gardens or orchards. Very often, host trees that have lots of mistletoes suffer from them as the triumph of mistletoes lead to poor growth and productivity and eventual death of such host plants. However in the other side, mistletoe is known as one of medical plants used in traditional/alternative medicine in Korea and other countries such as in treatment for cough, diabetes, hypertension, cancer, diuretic, smallpox, ulcer, skin infection and after child-birth (Ishizu et al., 2002; Kim et al., 2016; Osabede et al., 2004). Since mistletoe is a semi-parasitic plant, it is suggests that their bioactivities could also depend on their host plant. Camellia mistletoe, Korthalsella japonica (Thunb.) Engl., is one of the Korean mistletoes species which is distributed in Jeju island, Korea. Although there are a large number of studies about bioactivity of different mistletoe species, the antibacterial activity of Camellia mistletoe was not found. In the present study, extracts of camellia mistletoe obtained with different harvest time and solvents were investigated for in vitro antibacterial activity. 


\section{MATERIALS AND METHOD}

\section{Plant material and extraction}

Korean camellia mistletoe (Korthalsella japonica (Thunb.) Engl.) was collected in August and November of 2015, respectively, on Jeju Island, Korea. Korean camellia mistletoe was thoroughly rinse with tap and distilled water and was air-dried at room temperature. The air-dried mistletoe was grounded into powder using a blender. Dried powder (20 g) of camellia mistletoe was extracted with $100 \mathrm{~mL}$ of $100 \%$ methanol or $70 \%$ ethanol at $25^{\circ} \mathrm{C}$ for $72 \mathrm{~h}$ with constant shaking. The extract was then purified by using a Sep-Pak $\mathrm{C}_{18}$ cartridge and a $0.45 \mu \mathrm{m}$ membrane filter (Waters, Milford, MA, US), concentrated using a rotary evaporator (Buchi Rotavapor R-200, New Castle, DE, US), freeze dried and finally stored at $-20^{\circ} \mathrm{C}$ until further use. Dried extracts were reconstituted in dimethyl sulfoxide (DMSO, Amresco, Solon, Ohio, USA). DMSO acts as a solvent without changing any property of the methanol and ethanol extracts.

\section{Growth and maintenance of test microorganisms for antimicrobial studies}

Four strains were chosen for investigation of which one was reference bacteria: Gram positive ( $S$. epidermidis and $B$. subtilis subsps.) and Gram-negative (K. pneumonia and E. coli) organisms were stored at $-70^{\circ} \mathrm{C}$ and fresh subcultures were used for each experiment. S. epidermidis, B. subtilis subsps., $K$. pneumonia and $E$. coliwere grown under aerobic conditions in $1 \mathrm{~L}$ nutrient broth ( $1 \%$ polypeptone, $0.2 \%$ yeast extract, and $0.1 \%$ $\left.\mathrm{MgSO}_{4}, \mathrm{pH} 7.0\right)$ at $37^{\circ} \mathrm{C}$.

\section{Preparation of Inoculum}

The test microorganisms were pre-cultured in nutrient broth overnight in a rotatory shaker at $37^{\circ} \mathrm{C}$, centrifuged at 10,000 rpm for $5 \mathrm{~min}$, pellet was suspended in double distilled water. The cell density was monitored turbidimetrically at $600 \mathrm{~nm}$. The fungal inoculum (S. Epidermidis, B. subtilis subsps, K. pneumonia and $E$. coli) was prepared from the culture grown on agar-medium containing $1.5 \%$ agarose and the conidia were scraped using sterile spatula.

\section{Evaluation of antimicrobial activity}

The test microorganisms were seeded into respective medium by spread plate method $250 \mu \mathrm{L}$ with the overnight cultures of bacteria growth in nutrient broth. The in vitro antibacterial activity of the methanol and ethanol extracts of Korean camellia mistletoe was carried out by disc agar diffusion method (Elgayyar et al., 2001) with modification. Briefly, first a loop of each standard strain culture media was cultured on the plates, and then paper discs (from Advantec filter with $8 \mathrm{~mm}$ diameter) placed on agar-medium, plates were saturated with $10-40 \mu \mathrm{L}$ of the test compound and control allowed to dry and was introduced on the upper layer of the seeded agar plate with $15 \mathrm{mg} / \mathrm{disc}$ concentrations, were prepared in distilled water and was treated with methanol and ethanol extracts of Korean camellia mistletoe and placed in culture medium by sterile loop. Then it was fixed on the media with a light little pressure. After 12-18 h, the diameter of free zone was measured exactly by using a ruler in millimeters. The effects were compared with that of the standard antibiotic ampicillin (10 $\mu \mathrm{g} / \mathrm{disc})$ and vehicle (DMSO) alone served as control. All experiments were performed with 3 replicates.

\section{Statistical analysis}

All the assays were carried out in triplicates. The experimental results were expressed as mean \pm SD. The data were analysis using one way analysis of variance (ANOVA) using SPSS for Windows 12.0 (SPSS Inc. Chicago, IL, USA).

\section{RESULTS AND DISCUSSION}

The antibacterial activity of Korean camellia mistletoe extracts was assayed in vitro by agar disc diffusion against 4 bacterial species. Table 1 summarizes the microbial growth inhibition of both methanol and ethanol extracts of the Korean camellia mistletoe. The methanol extracts showed slight activity only against both gram positive and negative bacterial species, while the ethanol extracts on all the test organisms did not show any clear zone around the disc indicating no antimicrobial activity (Figures 1-4). On the contrary, $10 \mu \mathrm{g}$ of ampicillin (positive control) showed wide zones of inhibition on all the test organisms which is incomparable to the $15 \mathrm{mg} / \mathrm{disc}$ concentration of the plant extracts. DMSO negative control shows no zone of inhibition (Figures 1-4).

Table 1: Antimicrobial effects of methanol and ethanol extracts of $15 \mathrm{mg} / \mathrm{disc}$ Korean camellia mistletoe (Korthalsella japonica (Thunb.)Engl.) harvested in August and November of 2015, on S. epidermidis, B. subtilis subsps.,K. pneumonia and E. Coli.

\begin{tabular}{|c|c|c|c|c|c|}
\hline \multirow[b]{3}{*}{ Microorganism } & \multicolumn{4}{|c|}{ Degree of inhibition $^{a}$} & \multirow{3}{*}{ 泀 } \\
\hline & \multicolumn{2}{|c|}{ August } & \multicolumn{2}{|c|}{ November } & \\
\hline & 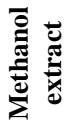 & 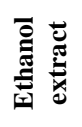 & 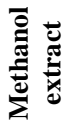 & 矛 & \\
\hline S. epidermidis & + & - & + & - & ++ \\
\hline B. subtilis subsps. & + & - & + & - & ++ \\
\hline K. pneumonia & + & - & + & - & ++ \\
\hline E. coli & + & - & + & - & ++ \\
\hline
\end{tabular}

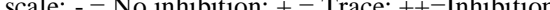

${ }^{\mathbf{b}}$ Positive control.

Different solvents have been reported to have the capacity to extract different phytoconstituents depending on their solubility or polarity in the solvent (Marjorie, 1999). Methanol extracts obtained in this study might have higher solubility for more of active antimicrobial phytoconstituents compared with ethanol extracts, consequently displaying the relative antimicrobial activity (Figures 1-4). It is known that the content of bioactive compounds in plant materials varies greatly with, for example processing, genotype, harvest time, growing environment and conditions (Karami et al., 2013). 


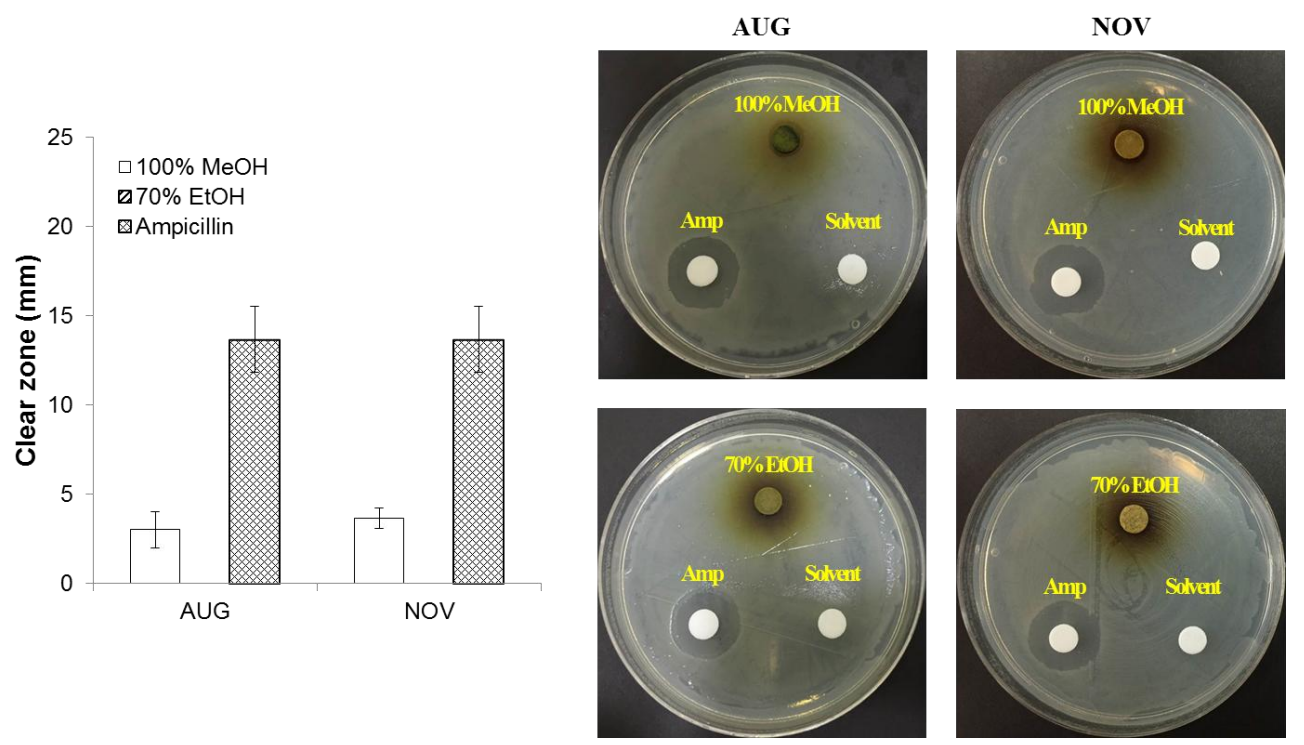

Fig. 1: Average diameter (mm) of microbial free zone area of methanol and ethanol extracts of Korean camellia mistletoe (Korthalsella japonica (Thunb.) Engl.) harvested in August and November of 2015, on S. epidermidis. Each value is expressed as mean \pm S.D. $(\mathrm{n}=3)$.
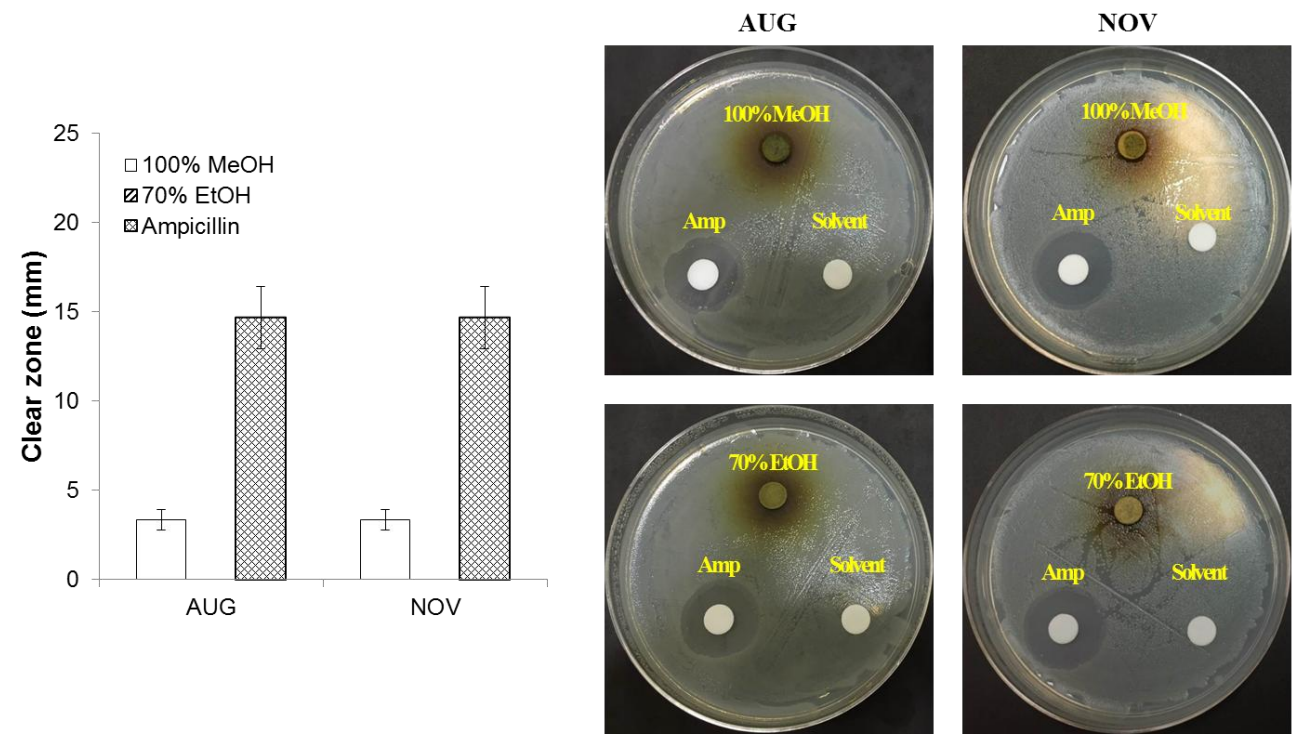

Fig. 2: Average diameter $(\mathrm{mm})$ of microbial free zone area of methanol and ethanol extracts of Korean camellia mistletoe (Korthalsella japonica (Thunb.) Engl.) harvested in August and November of 2015, on B. subtilis subsps. Each value is expressed as mean \pm S.D. $(\mathrm{n}=3)$.

In the present study, there were no significant differences between antimicrobial activity of the Korean camellia mistletoe harvested at August and November (Figures 1-4). These results may suggest that the concentrations of the active constituent in the extracts are too low for any appreciable antibacterial activity. It is also possible that the plant showed low or no inhibitory potential on test microorganisms only. Plants remain the most common source of antimicrobial agents (Bibitha et al., 2002; Maghrani et $a l .$, 2005). Many aromatic plants have been used traditionally in folk medicine as well as to extend the shelf life of foods, showing inhibition against bacteria, fungi and yeast (Hulin et al., 1998).
Biologically active compounds from natural sources have always been a great interest for scientists working in infectious diseases. The potential for developing antimicrobial from higher plants appears rewarding as it will result to the development of a phytomedicine to act against microbes. Plant based antimicrobials have enormous therapeutic potentials as they can serve the purpose with lesser side effects that are often associated with synthetic antimicrobials. Further studies will be needed to purify the bioactive compounds of the methanol extracts of Korean camellia mistletoe and characterize their phytochemical mode of action. 


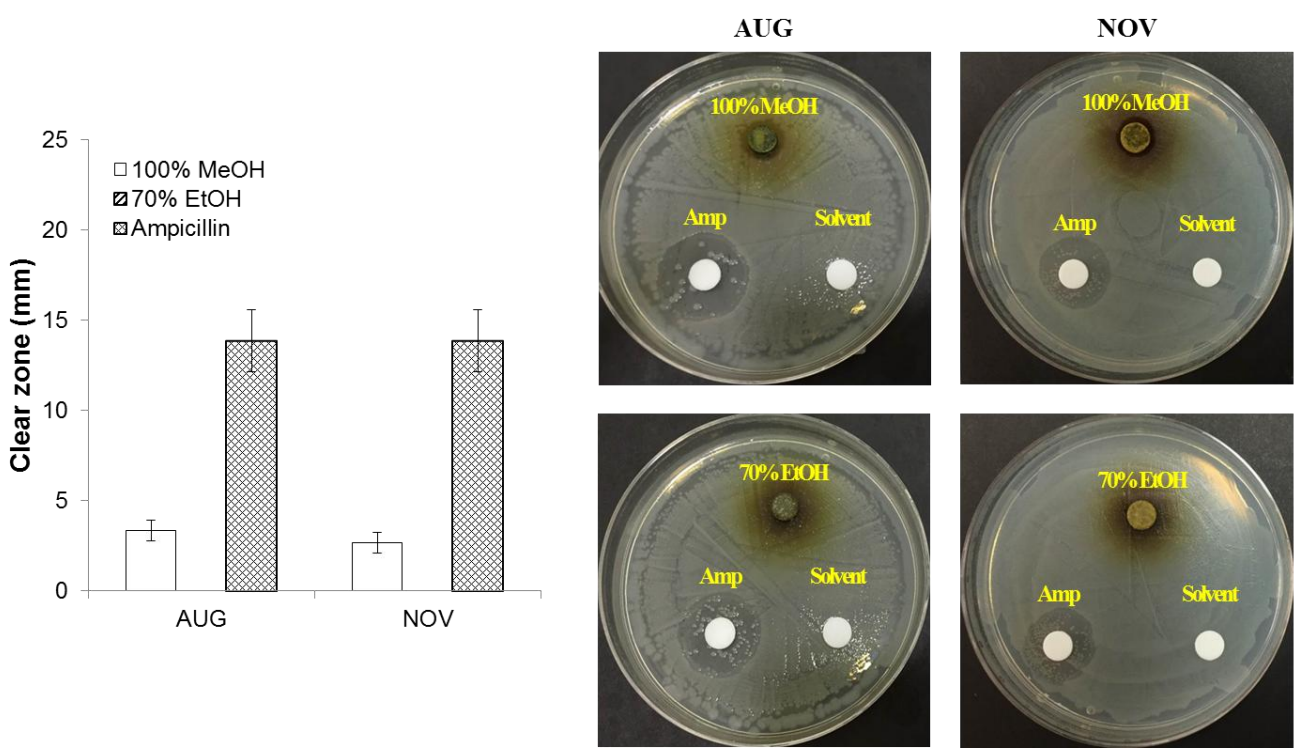

Fig. 3: Average diameter ( $\mathrm{mm}$ ) of microbial free zone area of methanol and ethanol extracts of Korean camellia mistletoe (Korthalsella japonica (Thunb.) Engl.) harvested in August and November of 2015, on K. pneumonia. Each value is expressed as mean \pm S.D. $(\mathrm{n}=3)$.

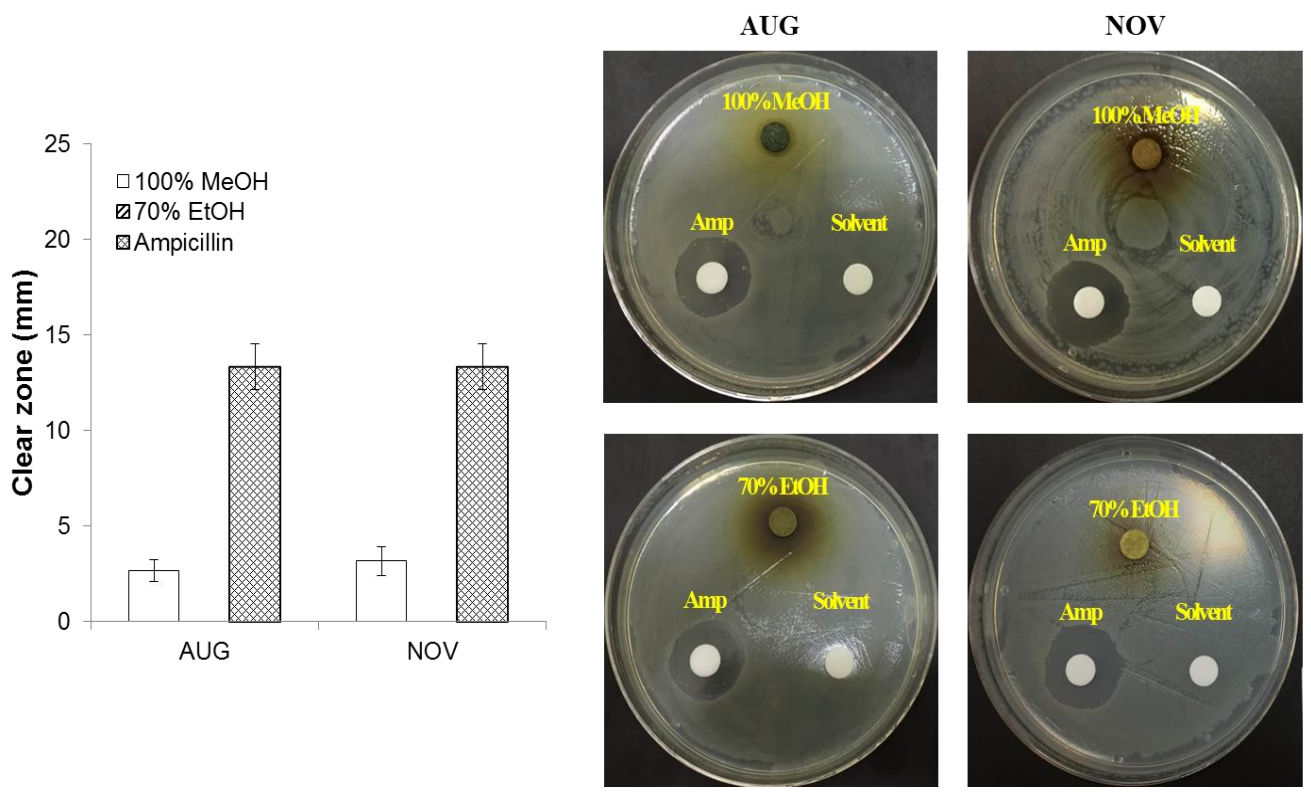

Fig. 4: Average diameter ( $\mathrm{mm})$ of microbial free zone area of methanol and ethanol extracts of Korean camellia mistletoe (Korthalsella japonica (Thunb.) Engl.) harvested in August and November of 2015, on E. coli. Each value is expressed as mean \pm S.D. $(\mathrm{n}=3)$.

\section{ACKNOWLEDGEMENT}

Financial support and sponsorship: This work was supported by Basic Science Research Program (2016R1A6A1A03012862 and 2014R1A1A2056292) through the National Research Foundation of Korea (NRF) funded by the Ministry of Education, Science and Technology, Republic of Korea.

Conflict of Interests: There are no conflicts of interest.

\section{REFERENCES}

Balandrin MF, Klocke JA, Wurtele ES, Bollinger WH. Natural plant chemicals: Sources of Industrial and Medicinal materials. Science. 1985; 228: 1154-1160.

Bibitha B, Jisha VK, Salitha CV, Mohan S, Valsa AK. Antibacterial activity of different plant extracts. Indian Journal of Microbiology.2002; 42: 361-363.

Cowan MM. Plant Products as antimicrobial agents. Clinical Microbiology Review. 1999; 12(4): 264-582.

Elgayyar M, Draughon FA, Golden DA, Mount JR. Antimicrobial activity of essential oils from plants against selected 
pathogenic and saprophytic microorganisms. Journal of Food Protection. 2001; 64(7): 1019-1024.

Hulin V, Mathot AG, Mafart P, Dufosse L. Antimicrobioal properties of essential oils and flavor compounds. Sciences des Aliments. 1998; 18: 563-582.

Ishizu T, Winarno $\mathrm{H}$, Tsujno $\mathrm{E}$, Morita $\mathrm{T}$, Shibuya $\mathrm{H}$. Indonesian Medicinal Plants. XXIV. Stereochemical structure of Perseitol$\mathrm{K}^{+}$complex isolated from the leaves of Scurrulafusca (Loranthaceae), Chemical and Pharmaceutical Bulletin. 2002; 50(4): 489492.

Karami Z, Mirzaei H, Emam-Djomeh Z, Sadeghi Mahoonak AR, Khomeiri M. Effect of harvest time on antioxidant activity of Glycyrrhiza glabra root extract and evaluation of its antibacterial activity. International Food Research Journal. 2013; 20(5): 2951-2957.

Kim MK, Yun KJ, Lim DH, Kim JJ, Jang YP.Antiinflammatory properties of flavone di-C-glycosides as active principles of Camellia mistletoe, Korthalsella japonica. Biomolecules \& Therapeutics. 2016; 019: 1-8.
Maghrani M, Zeggwah N, Michel J, Eddouks M. Antihypertensive effect of Lepidium sativum in spontaeneously hypertensive rats. Journal of Ethnopharmacology. 2005; 102(1-2):193197.

Marjorie MC. Plant products as antimicrobial agents.Clinical Microbiology Reviews.1999; 12 (4): 564-582.

Osadebe PO, Okide GB, Akabogu IC. Study on anti-diabetic activities of crude methanolic extracts of Loranthus micranthus (Linn.) sourced from five different host trees. Journal of Ethnopharmacology. 2004; 95(2-3): 133-138.

Reiner R. Antibiotic: An introduction. New Horn Press. 1984.

\section{How to cite this article:}

Kang DH, Kim MY. Antimicrobial activity of Korean camellia mistletoe (Korthalsella japonica (Thunb.)Engl.)extracts. J App Pharm Sci, 2016; 6 (10): 226-230. 